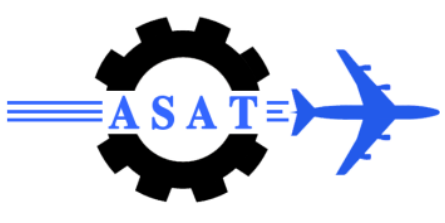

\title{
Realization and Evaluation of IIR Seeker via Hardware-in-the-Loop Simulation
}

\author{
Ahmed Eyssa $^{*}$, G.A. El-Sheikh ${ }^{\dagger}$, Y.Z. El-Halwagy ${ }^{\ddagger}$ and I.A. Abd El-Dayem ${ }^{\S}$
}

\begin{abstract}
The simulation is indispensable for systems design and analysis especially flight control systems. Among the simulation techniques is the Hardware-in-Loop-Simulation (HILS) which links the hardware and software for synthesis with the objective of overcoming any of the simplifying assumptions during modeling. The benefits of this type of simulation are to cut down the required number of flight trials and to increase the confidence level of realizability of the system design. Therefore, this paper addresses the implementation and evaluation of Image Infra-Red (IIR) seeker system, where the system integration is carried out via HILS for research and development (R\&D). The IIR seeker components including; thermal camera, video tracker, and steering system are analyzed and tested individually. Interfacing problems are deeply analyzed and figured out in the assembled overall system for performance evaluation of IIR seeker. The real thermal target coordinates provided from IIR seeker are applied to a six-degrees-of freedom (6DOF) flight simulation model for homing guidance systems. The experimental setup associated with the system is presented from which the simulation and experimental results highlight the effect of various components constituting the IIR seeker. Smoothing filters are proposed to enhance the interception of targets performing uncertain|random maneuvers and to overcome the dynamics of the video tracker and the steering system towards achieving missile-target interception with good trajectory.
\end{abstract}

Keywords: Homing Guidance Systems, IIR Seekers, HILS

\section{Introduction}

Homing guidance system (sometimes it is called Two-Point Guidance since the guidance process is mainly dependent upon the target and the missile positions) is the most common form of guidance used in anti-air missiles today. Homing guidance systems may operate thanks to the fact that targets usually emit or reflect some form of energy, which is received by the missile homing head (seeker). This energy may be in the form of heat (infrared radiation), light, sound, or electromagnetic radiation. In a homing guidance system, the guidance or control signals are produced directly in the missile (onboard) using the information received, mutual position of the missile and target, by the missile homing head. The homing headlseeker consists of (1) sensitive detector used to receive the energy radiated or reflected from target, and (2) a coordinator used to determine the direction of the target with regard to the missile and the relative distance. Shaped from these values are the guidance

\footnotetext{
*Egyptian Armed Forces, Egypt, ahmed_eyssa@hotmail.com

$\dagger$ Egyptian Armed Forces, Egypt, gaelsheikh@gmail.com

+ Egyptian Armed Forces, Egypt, ehalwagy@ hotmail.com

$\S$ Egyptian Armed Forces, Egypt.
} 
commands for the autopilot so that the missile moves to intercept the target along the trajectory determined by the guidance method. The homing guidance systems may be categorized into three primary forms of guidance: active, semi active, and passive [6].

Active radar homing uses a transceiver on the missile to provide the guidance signals necessary to keep the seeker pointed directly at the target and the missile then looks at this angle off its own centerline to guide itself. Seeker resolution is based on the size of the antenna, so in a smaller missile these systems are useful for attacking only large targets, ships or large bombers for instance. Active radar systems remain in widespread use in anti-shipping missiles, and in fire and forget air-to-air missile systems.

Semi-active radarllaser homing (SARHISALH) systems combine a radarllaser receiver on the missile with a radarllaser illuminator located elsewhere. Since the missile is typically being launched after the target was detected using a powerful radarllaser system. SARHISALH is by far the most common all weather guidance solution for anti-aircraft systems, both ground and air launched.

PassivelInfrared homing guided missiles detect the heat generated by the target and home on. Typically, it is used in the anti-aircraft and anti-vehicle role to track the heat of engines due to which the guidance is sometimes referred to as heat-seeking. However, the revolution of technology enables great developments in this concept, which is now based on infrared imaging (IIR or I2R), and consequently it is successfully used with missiles against air and groundlsurface targets.

For the purpose of research investigation, analysis and development, HILS is utilized with a 6DOF flight simulation model for the underlying missile system [7]. Within this experimental setup, different investigation-activities are carried out including the IIR seeker evaluation, the implementation of thermal target scene, and interfacing various hardware components constituting the simulation loop. Passive systems may be equipped with an imaging seeker that operates in the visual region TV and low-light level TV, and in the middle IR atmospheric transmission window (3 to $5 \mu \mathrm{m}$ ) or in the far IR atmospheric transmission window $(8$ to $14 \mu \mathrm{m})$ [11]. The experiment is used to analyze the spectrum radiation of any infrared source (hot body) using the Plank's law [8,9] which represents the spectral characteristic of an ideal blackbody. HILS approach should be carried out on real-time basis to accommodate any actual components within the simulation loop. The complete hardware in loop simulation for the passive homing missile guidance and control system is an indoor test facility for research and development of a guidance and control algorithm. Two filters are proposed to enhance the interception of targets performing uncertain maneuvers.

\section{6DOF Flight Simulation}

The simulation is a very important tool for design and development of most systems; especially in the field of guidance and control [2].The 6DOF model is a mathematical description of the physical system in the form of a set of differential equations whose inputs correspond to the physical stimuli and whose outputs describe the system behavior [3, 4]. Figure 1 depicts the major parts of this simulation model including: missile-target geometry, guidance, autopilot, airframe, and kinematics. 


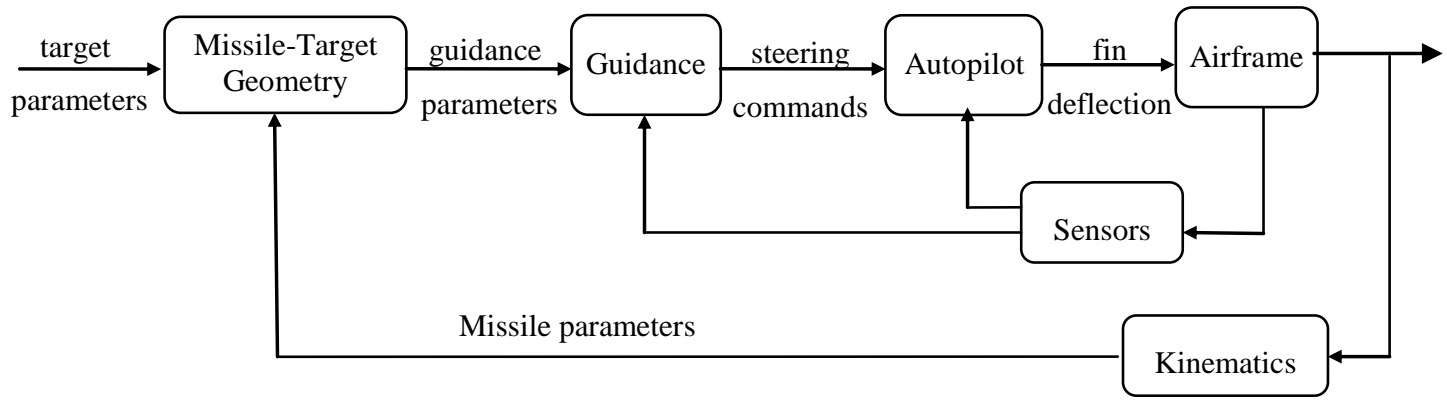

Fig. 1 Simplified block diagram of main simulation modules

This set of differential equations is programmed to yield the flight simulation model code written under VISUAL c++ environment with a graphical user interface (GUI), Fig. 2. This GUI allows the user to insert the target parameters and it shows the real processing time, the miss distance, and the target status.

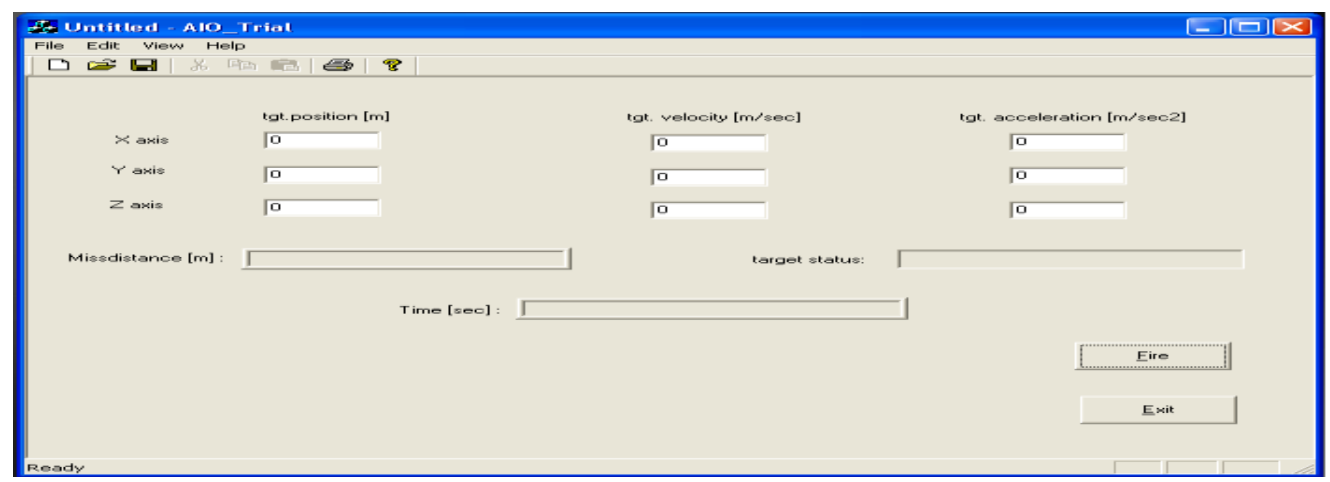

Fig. 2 Graphical user interface of the flight simulation model

The simulation is conducted using the designed 6DOF model with various engagement scenarios including fixed targets, non-maneuvering targets, and maneuvering targets in the form of case studies. Two case studies are considered, where Fig. 3 depicts the engagement scenario and Table 1 presents the target initial data for the first case study. Figure 4 depicts the engagement scenario and Table 2 shows the target initial data for the second case study.

The results show that increasing the target maneuvers result in a large miss distance and even target miss.

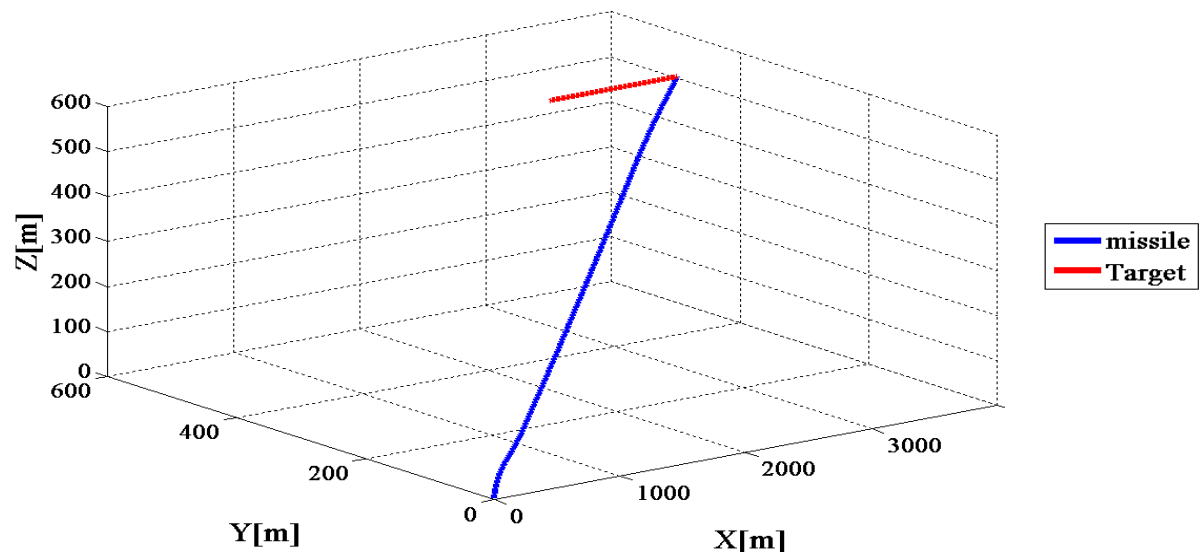

Fig. 3 Missile -Target engagement scenario for first case study 
Table 1 Target parameters for first case study

\begin{tabular}{c|c|c|c|c|c|c|c|c|c|c|c}
\hline \hline \multicolumn{6}{c|}{ Target velocity [m/s] } & \multicolumn{5}{|c|}{ Target position [m] } & \multicolumn{5}{c|}{ Target Maneuver [m/s $\left.{ }^{2}\right]$} & Miss \\
\hline $\mathrm{v}_{\mathrm{t}_{\mathrm{x}}}$ & $\mathrm{v}_{\mathrm{t}_{\mathrm{y}}}$ & $\mathrm{v}_{\mathrm{t}_{\mathrm{z}}}$ & $\mathrm{x}_{\mathrm{t}}$ & $\mathrm{y}_{\mathrm{t}}$ & $\mathrm{z}_{\mathrm{t}}$ & $\mathrm{a}_{\mathrm{x}}$ & $\mathrm{a}_{\mathrm{y}}$ & $\mathrm{a}_{\mathrm{z}}$ & $\begin{array}{c}\text { Start } \\
\text { time }\end{array}$ & $\begin{array}{c}\Delta \mathrm{t} \\
{[\mathrm{s}]}\end{array}$ & $\begin{array}{c}\text { distance } \\
{[\mathrm{m}]}\end{array}$ \\
\hline 100 & 0 & 0 & 3000 & 500 & -500 & 0 & 0 & 0 & 0 & 0.02 & 0.06 \\
\hline \hline
\end{tabular}

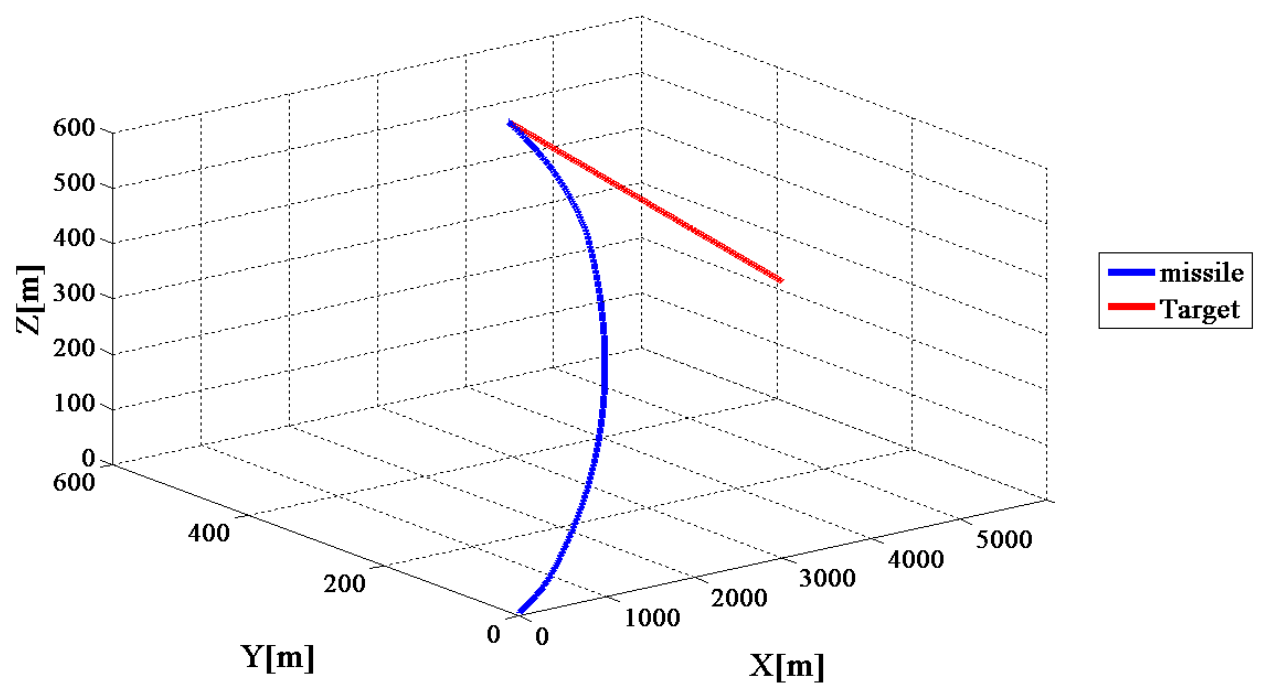

Fig. 4 Missile-Target engagement scenario for second case study

Table 2 Target parameters for second case study

\begin{tabular}{|c|c|c|c|c|c|c|c|c|c|c|c|}
\hline \multicolumn{3}{|c|}{ Target velocity [m/s] } & \multicolumn{3}{|c|}{ Target position [m] } & \multicolumn{5}{|c|}{ Target Maneuver $\left[\mathrm{m} / \mathrm{s}^{2}\right]$} & \multirow{2}{*}{$\begin{array}{c}\text { Miss } \\
\text { distance } \\
{[\mathrm{m}]}\end{array}$} \\
\hline$v_{t_{x}}$ & $\mathrm{v}_{\mathrm{t}_{\mathrm{y}}}$ & $\mathrm{v}_{\mathrm{t}_{\mathrm{z}}}$ & $x_{t}$ & $\mathrm{y}_{\mathrm{t}}$ & $\mathrm{Z}_{\mathrm{t}}$ & $a_{x}$ & $\mathrm{a}_{\mathrm{y}}$ & $a_{z}$ & $\begin{array}{l}\text { Start } \\
\text { time }\end{array}$ & $\begin{array}{c}\Delta \mathrm{t} \\
{[\mathrm{sec}]}\end{array}$ & \\
\hline 0 & 0 & 0 & 3000 & 0 & -500 & 20 & 10 & 0 & 0 & 0.02 & 0.59 \\
\hline
\end{tabular}

\section{The IIR Seeker}

The simple tracking system consists of viewing element (TV camera), scene segmentation and selection means, camera steering means (a gyro), and monitor [1]. The IIR seeker components (thermal camera, video tracker, and steering system) are analyzed and tested individually then assembled and the performance of IIR seeker is evaluated using the state space system identification technique $[10,12]$. The present state of electro-optical guidance system technology can be divided into three broad classes of devices [5]:

1. Non-imaging IR guidance systems operate in either the near or middle IR band (3 to $5 \mu \mathrm{m}$ ).

2. Imaging guidance systems (IIR and TV) operate in the visible or middle IR band ( 3 to $5 \mu \mathrm{m}$ ) or far IR band ( 8 to $14 \mu \mathrm{m}$ ); imaging IR seeker.

3. Laser seekers are the most commonly used being $1.06 \mu \mathrm{m}(\mathrm{Nd}-\mathrm{YAG})$, or $10.06 \mu \mathrm{m} \mathrm{C02}$ laser. 


\subsection{Thermal Imaging Camera}

The camera IR113 is an infrared imaging module qualified for military Standard, where the detector type is un-cooled FPA micro-bolometer and the spectral response is $8-14 \mu \mathrm{m}$.

Figure 5 depicts the thermal imaging camera IR113 mounted on a two-axis turntable.

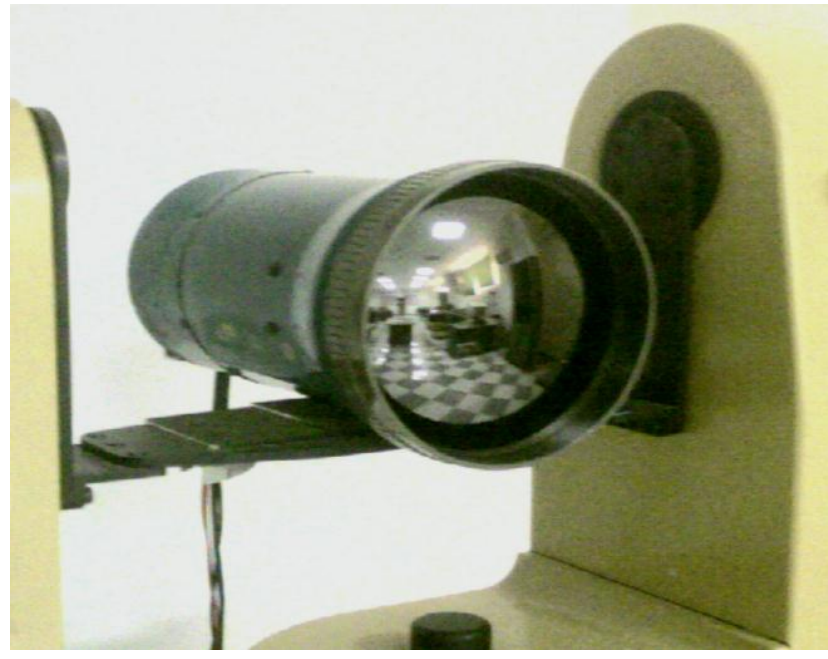

Fig. 5 Thermal imaging camera IR113

\subsection{Video Tracker}

The Automatic Video Tracker (ADEPT36 AVT) automatically detects and tracks a single target in the video picture from either a TV Camera or Thermal Imager. The AVT interface is carried out via serial data links. Figure 6 depicts the Video Tracker Front Panels.

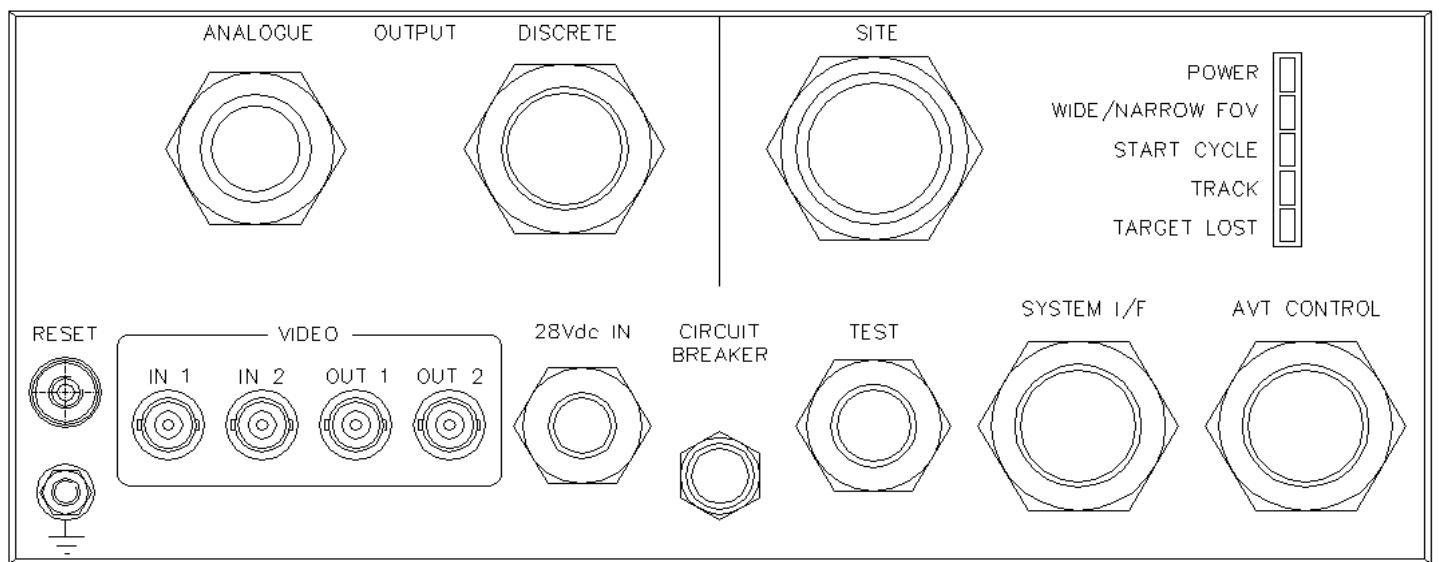

Fig. 6 Video Tracker Front Panels

\subsection{Turntable}

The Mantis two axis motorized platform, Fig. 7, moves without restriction in azimuth and within $\pm 90^{\circ}$ in elevation. The platform interface is serial data links with positional accuracy 1 [mils].

\subsection{Thermal Target Scene}

The thermal target scene, Fig. 8, simulates the real target motion in laboratory with constant speeds, acceleration, and in two directions. It consists of dc motor, thermal target, aluminum rod, carriage, group of gears, tripod, reverse switch, and dc power supply. 


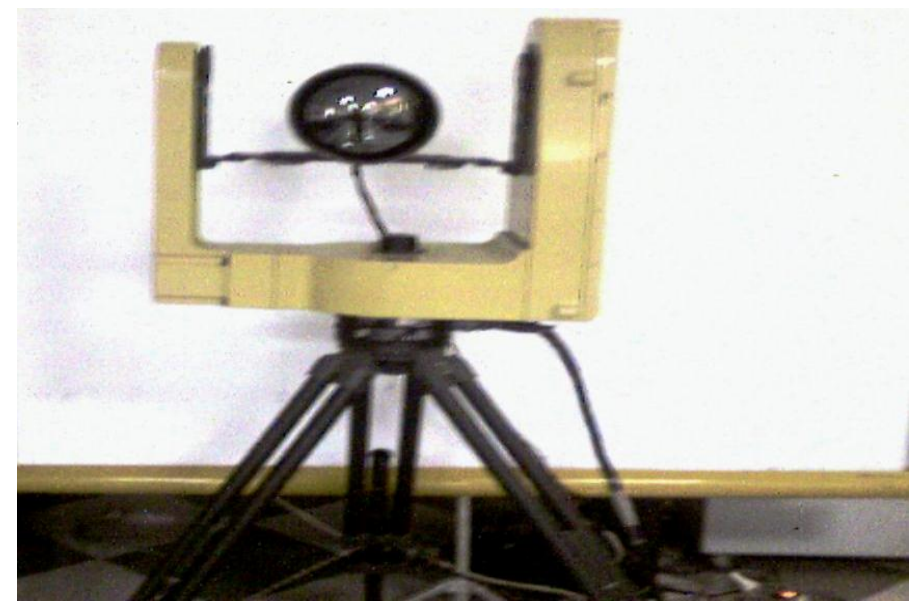

Fig. 7 The Mantis two axis motorized

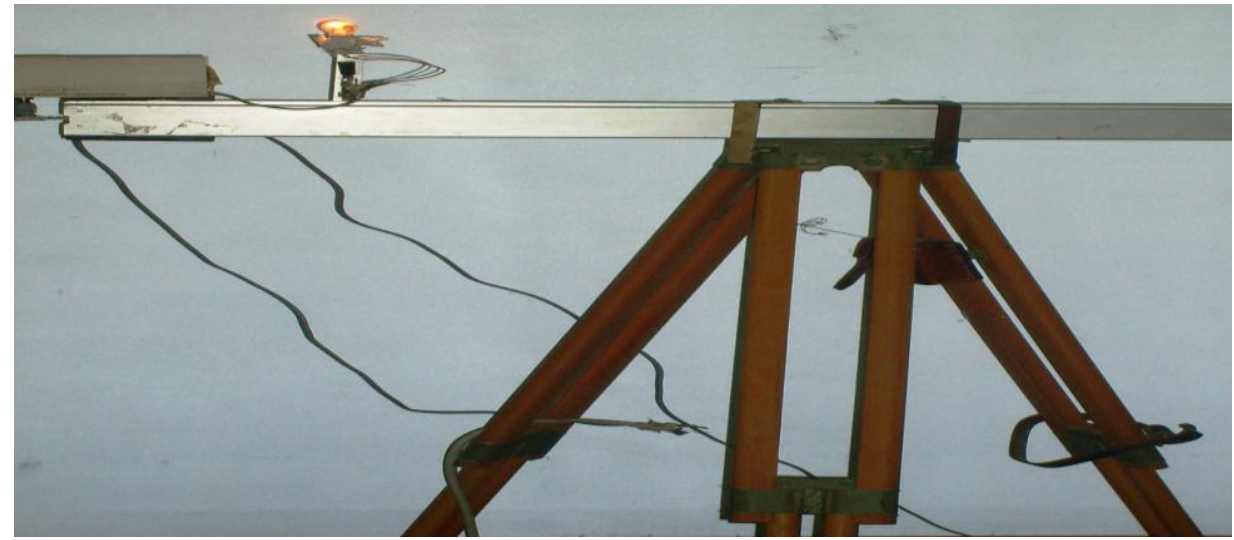

Fig. 8 The thermal target scene

\section{Experimental Setup and Results}

The HILS test facility is used to test and evaluate the proposed guidance algorithm against targets in presence of uncertainties and un-modeled dynamics. The development of this work started with a complete software for modeling and simulation of passive homing guided missile. This step is followed with a major stage of developing the controllable turntable associated with serial port interface. The IIR seeker provides the 6DOF flight simulation model with the target position or the line of sight (LOS) rates instead of simulating the target coordinates. Necessary signal conditioning and/or acquisition algorithms are developed. The software program acquires data from video tracker and controls its position, controls the turntable to track the thermal target, calculates the target coordinates, and provides the real target coordinates to the flight simulation model. It is written in a computer code under visual c++ environment. Figure 9 depicts this experimental setup, where the thermal target scene is installed at 15 meter distance from the thermal imaging camera in the laboratory and many case studies are considered.

\subsection{Case Study 1}

The turntable is not used as inner track loop of the seeker. The thermal target move with constant speed at constant height from left to right within the FOV of thermal imaging camera for 12 seconds without smooth filter. Figure 10 depicts a comparison between the missile trajectories when using simulated or real target trajectory and clarifies that there is no interception; the miss-distance equals $D_{\text {miss }}=140.4$ [m]. 


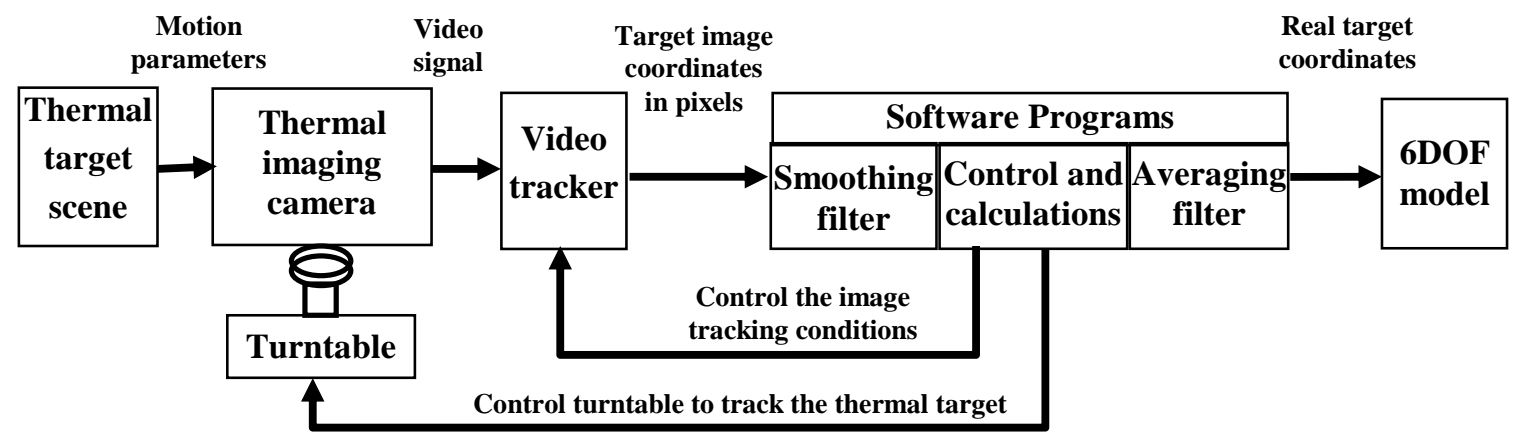

Fig. 9 Experimental setup
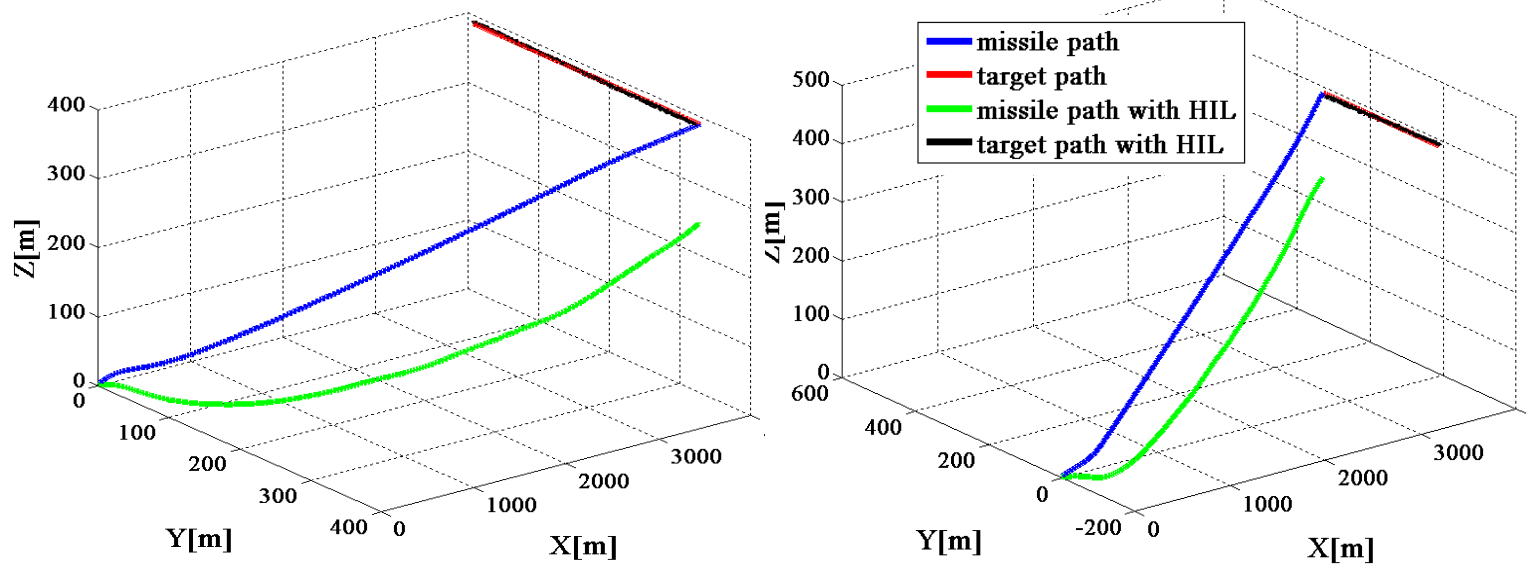

Fig. 10 Missile and target trajectories (Case-1)

\subsection{Case Study 2}

The same data as case study- 1 is used but with a low-pass smoothing filter that has $10 \mathrm{HZ}$ cutoff frequency and it is utilized to suppress the high frequency noise. The time constant $(\tau)$ of cascaded second order low-pass-filter is chosen to be equal to $\tau=0.1[\mathrm{~s}]$, the frequency response of which is shown in Fig. 11a and its effect on smoothing the measured target coordinates is shown in Fig. 11b. The transfer function of the smoothing filter $\left(\mathrm{G}_{\mathrm{sf}}\right)$ is identified of second order and has the form;

$$
\mathrm{G}_{\mathrm{sf}}=\frac{1}{0.001 \mathrm{~s}^{2}+0.1 \mathrm{~s}+1} \text { or } \mathrm{G}_{\mathrm{sf}}=\frac{-1.3455 \mathrm{~s}+123.2703}{\mathrm{~s}^{2}+22.172 \mathrm{~s}+123.3019}
$$

Using the filtered or smoothed target coordinates; a comparison between the missile trajectories when using simulated and real target trajectories are shown in Fig. 12 which clarifies that there is interception with miss-distance $\mathrm{D}_{\text {miss }}=0.4[\mathrm{~m}]$.

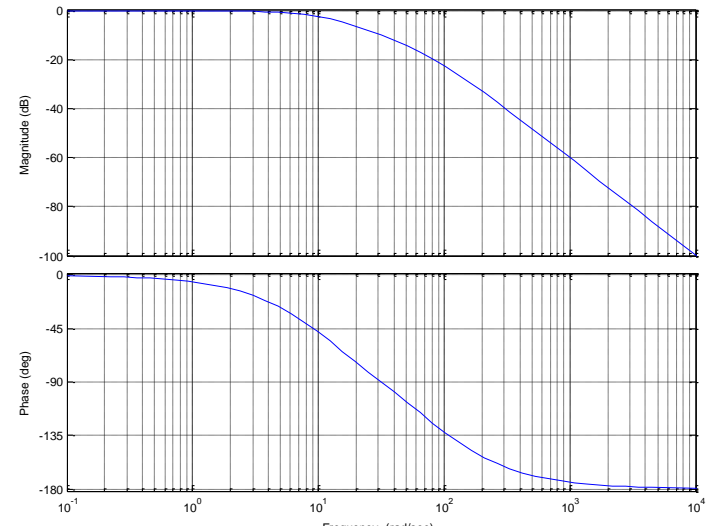

Fig. 11a Frequency response of smoothing filter

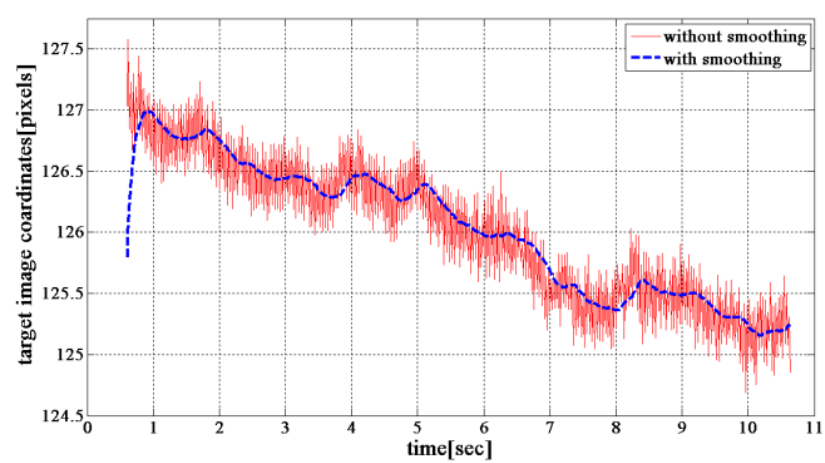

Fig 11b The effect of smoothing filter 

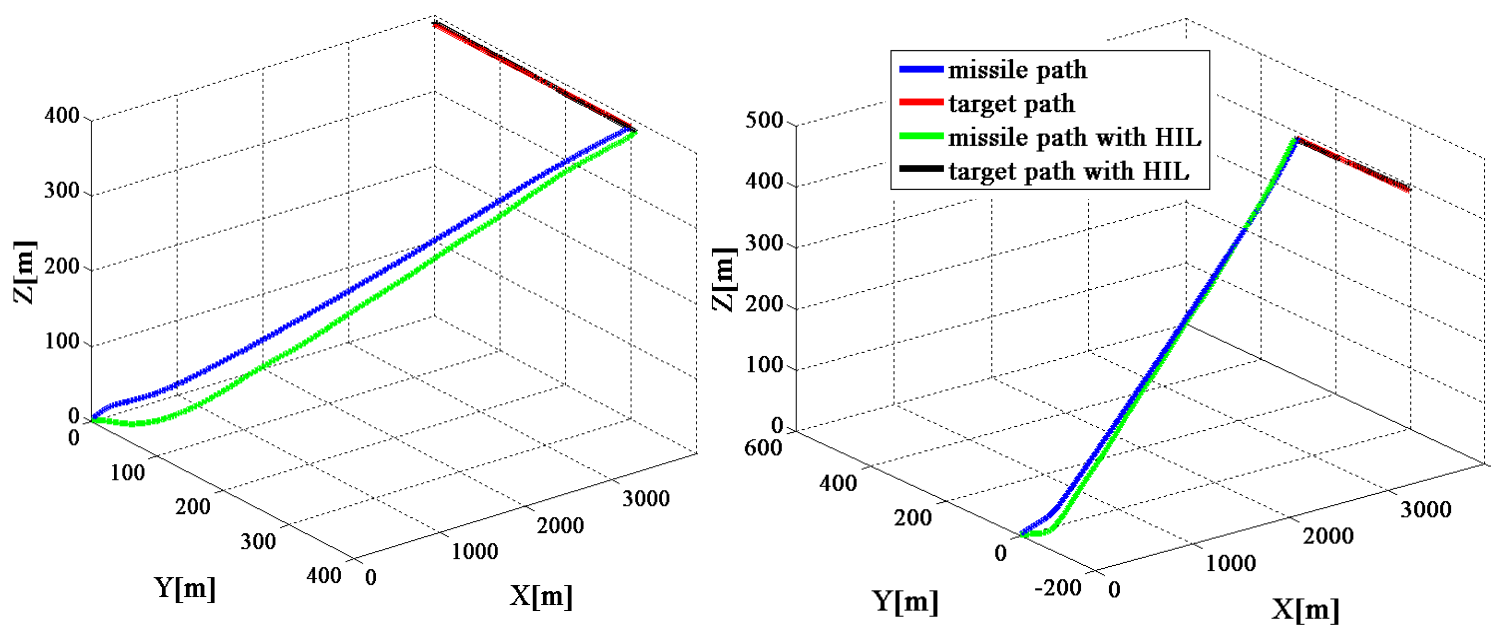

Fig. 12 Missile and target trajectories (Case-2)

\subsection{Case Study 3}

The turntable is used as the inner tracking loop of the seeker. The thermal target moves with constant speed at constant height from right to left within the FOV of the thermal imaging camera for 12 seconds with the smoothing filter. A comparison between the missile trajectories when using simulated or real target trajectory are shown in Fig. 13 which clarifies that there is no interception.
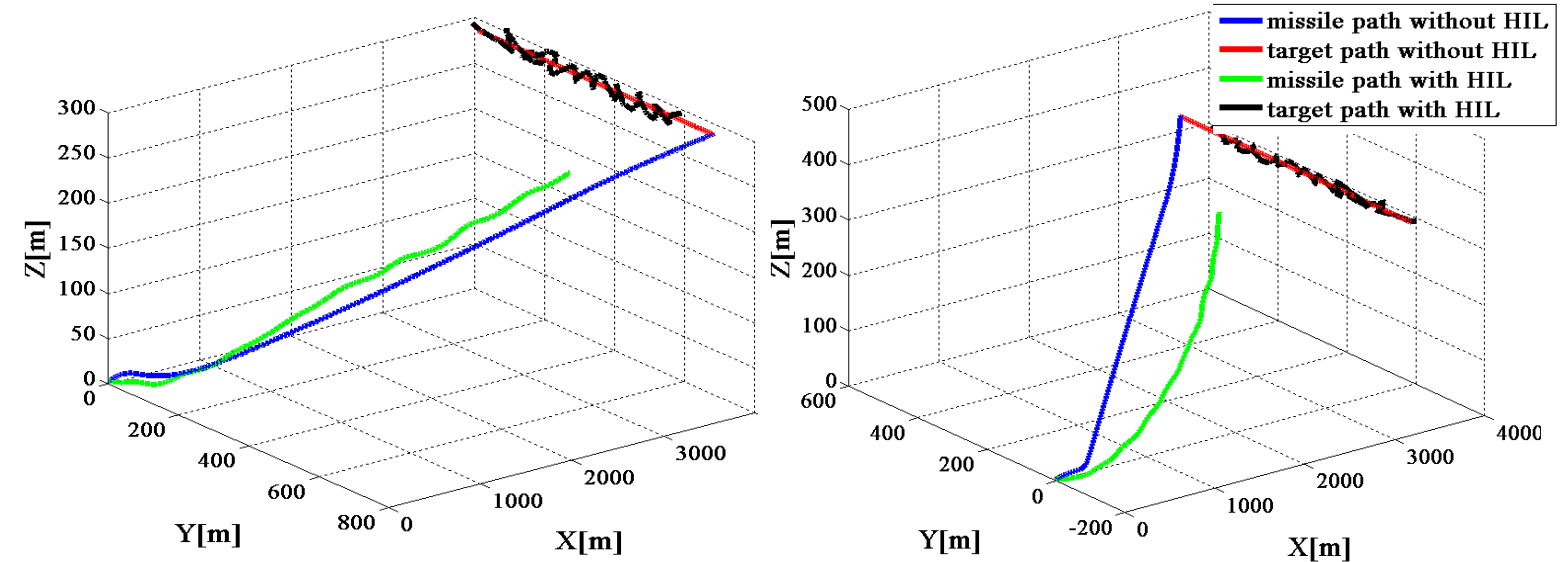

Fig. 13 Missile and target trajectories with seeker tracking

\subsection{Case Study 4}

To enhance the jerky nature of measured target coordinates, each target parameter is replaced with the average of its neighborhood. This neighborhood is to be designed as its increase enhances the image to certain degree after which the image will be corrupted. This averaging filter is given by the formula:

$$
\mathrm{B}_{\mathrm{k}}=\frac{1}{\mathrm{n}} \sum_{\mathrm{i}=\mathrm{k}+1}^{\mathrm{n}+\mathrm{k}} \mathrm{A}_{\mathrm{i}}
$$

where, $A_{i}$ is the filter input, $B_{k}$ is the output, $n$ is the averaging array length, and $(k=0,1,2, .$. is the order of the filter output. The operation of this filter can be described in steps as follows, assuming $n=25$, 
Step1:

\begin{tabular}{|l|l|l|l|l|l|}
\hline $\mathrm{a}_{25}$ & $\mathrm{a}_{24}$ & $\mathrm{a}_{23} \ldots \ldots$ & $\mathrm{a}_{3}$ & $\mathrm{a}_{2}$ & $\mathrm{a}_{1}$ \\
\hline
\end{tabular}

The first output value of filter $=\left(a_{25}+a_{24}+a_{23}+\ldots \ldots \ldots \ldots .+a_{3}+a_{2}+a_{1}\right) / 25$

Step2:

\begin{tabular}{|l|l|l|l|l|l|}
\hline $\mathrm{a}_{26}$ & $\mathrm{a}_{25}$ & $\mathrm{a}_{24} \ldots \ldots$ & $\mathrm{a}_{4}$ & $\mathrm{a}_{3}$ & $\mathrm{a}_{2}$ \\
\hline
\end{tabular}

The second output value of filter $=\left(a_{26}+a_{25}+a_{24}+\ldots \ldots \ldots \ldots a_{4}+a_{3}+a_{2}\right) / 25$

Step3:

\begin{tabular}{|l|l|l|l|l|l|}
\hline $\mathrm{a}_{27}$ & $\mathrm{a}_{26}$ & $\mathrm{a}_{25} \ldots \ldots$ & $\mathrm{a}_{5}$ & $\mathrm{a}_{4}$ & $\mathrm{a}_{3}$ \\
\hline
\end{tabular}

The third output value of filter $=\left(a_{27}+a_{26}+a_{25}+\ldots \ldots \ldots \ldots . a_{5}+a_{4}+a_{3}\right) / 25$

The effect of this averaging filter upon measured target coordinates is shown in Fig. 14 with different length.

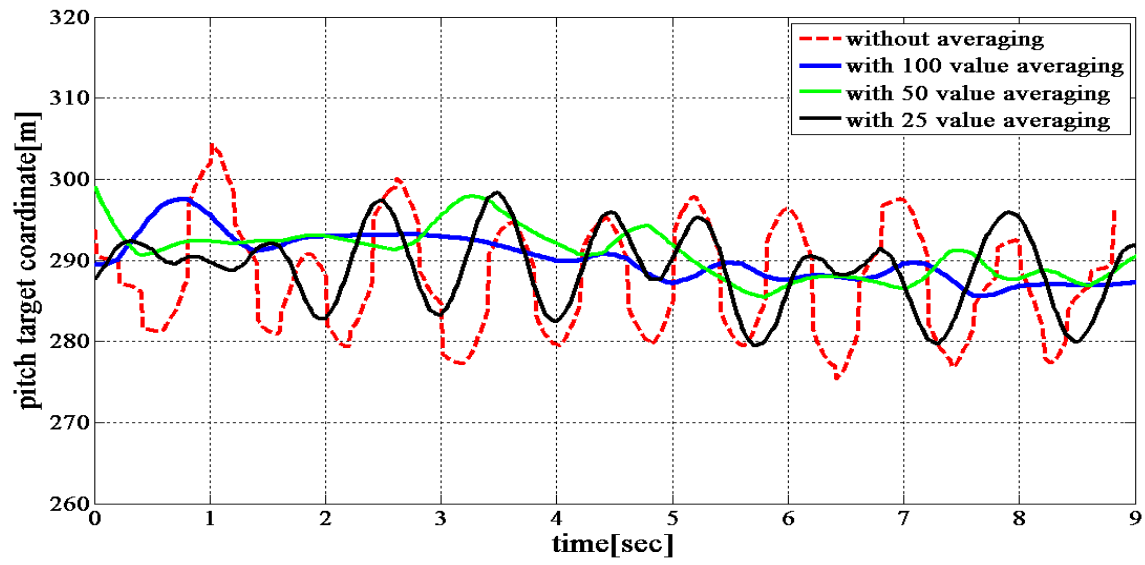

Fig. 14 The effect of different (n) values averaging filter

The same data of case study-3 is used but with 25 values averaging filter to smooth the target coordinates provided from the seeker in meters. Using this filter, a comparison between the missile's trajectories with simulated or real target trajectory are shown in Fig. 15, which clarifies that there is no interception with miss-distance $\mathrm{D}_{\text {miss }}=41.4[\mathrm{~m}]$.
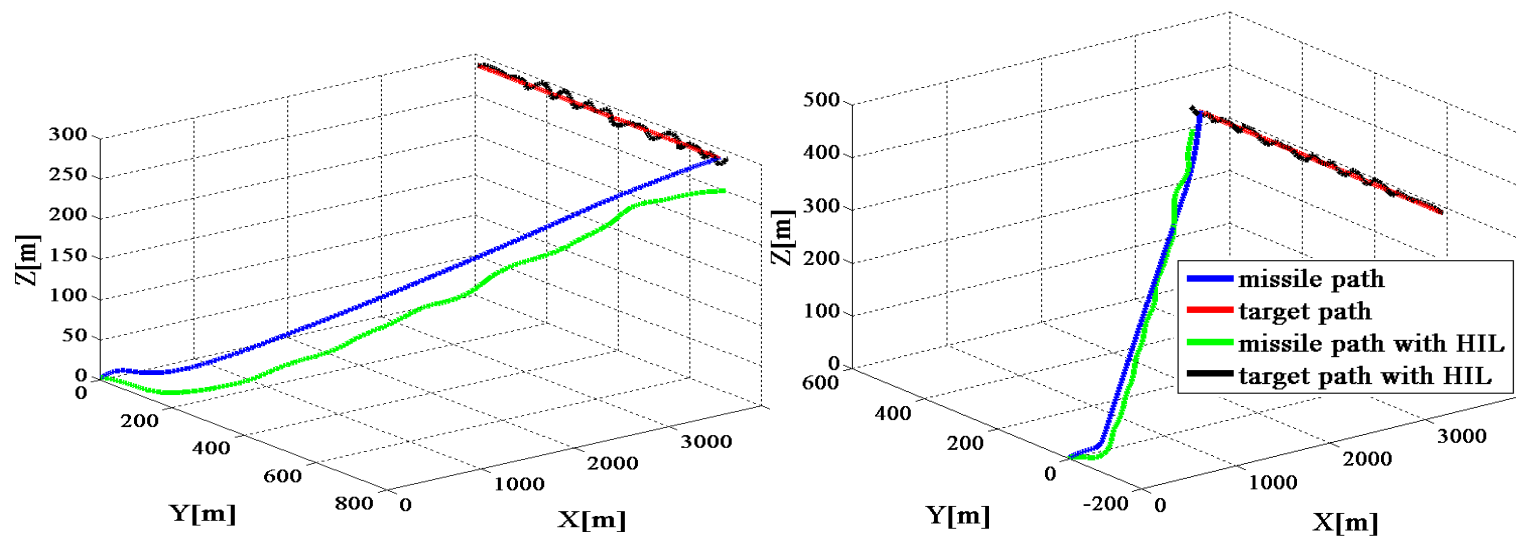

Fig. 15 Missile and target trajectories with seeker tracking and 25 value average filter 


\subsection{Case Study 5}

The same data of case study- 3 is used but with 50 values averaging filter to smooth the target coordinates in meters provided from the seeker. Thus, the missile trajectories using simulated or real target trajectory and the new filter are shown in Fig. 16, which clarifies that there is interception with miss-distance $\mathrm{D}_{\text {miss }}=4.74[\mathrm{~m}]$.
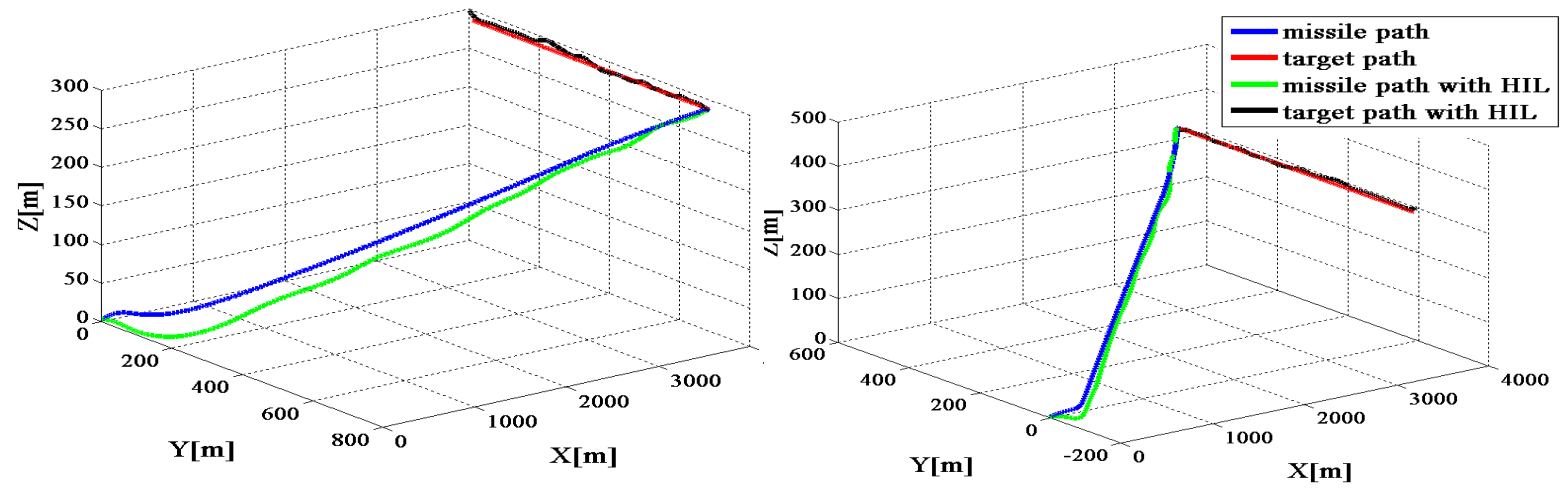

Fig. 16 Missile and target trajectories with seeker tracking and 50 value average filter

\subsection{Case Study 6}

The same data of case study- 3 is used but with 100 values averaging filter to smooth the target coordinates in meters provided from the seeker. The effect of the 100 values averaging filter on measured target coordinates is shown in Fig. 17 and its transfer function $\left(G_{a f}\right)$ is identified of second order and has the form,

$\mathrm{G}_{\mathrm{af}}=\frac{0.068301 \mathrm{~s}+0.33895}{\mathrm{~s}^{2}+0.055062 \mathrm{~s}+0.34252}$

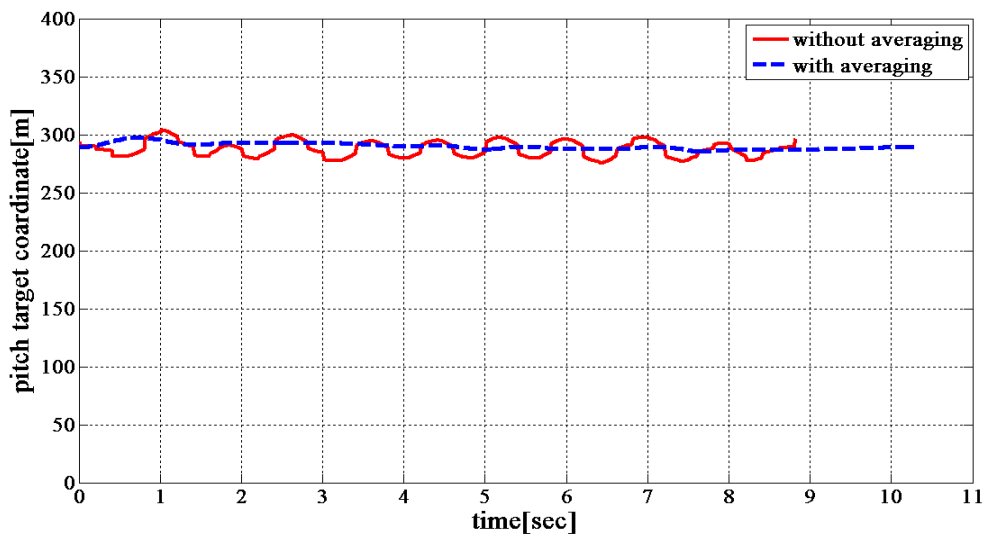

Fig. 17 The effect of 100 value averaging filter

Then, a comparison between the missile trajectories when using simulated or real target trajectory is shown in Fig. 18, which clarifies that there is interception with less miss distance, $\mathrm{D}_{\text {miss }}=0.8[\mathrm{~m}]$. 

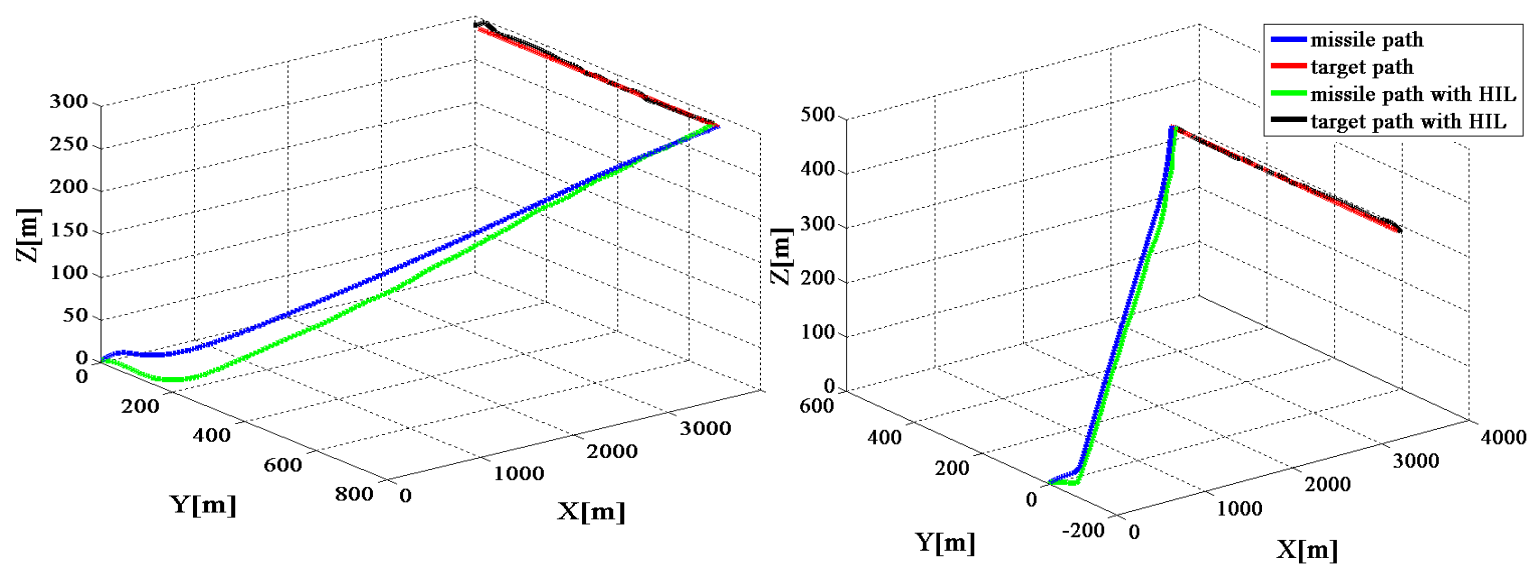

Fig. 18 Missile and target trajectories with seeker tracking and 100 value average filter

\section{Conclusions}

Hardware in-loop simulation for missile system is an indispensible step towards the system investigation, analysis and development. Basic requirement step is the hardware interfacing of various components constituting the simulation loop. The paper presented the complete hardware in loop simulation for the passive homing missile guidance and control as an indoor test facility for research and development of the guided missiles. This testing facility is used to evaluate the conventional guidance method and compare its performance with the proposed approach. The obtained results show that smoothing filters are necessary to enhance the interception of targets performing uncertain maneuvers.

\section{References}

[1] Abd El-Maarouff, A., IR/LASER Guidance and Image Tracking Systems and Their Passive Countermeasures, M.Sc. Thesis, Guidance Department, the M.T.C., Cairo, 2001.

[2] Calise A., S. Lee, and M. Sharma; Direct Adaptive Reconfigurable Control of a Tailless Fighter Aircraft, AIAA Guidance, Navigation, and Control Conference, pp. 88-97, 1998.

[3] Carnahan B., H. A. Luther, and J. O. Wilkes, Applied Numerical Methods, John Wiley \& Sons Inc., New York, U.S.A., 1969.

[4] Centuri Technical Information Report; Calculating the Centre of Pressure, Catalogue No. TIR-33.

[5] Deyerle, C., Advanced Infrared Missile Counter-Countermeasures, J. Electronic Defense, Jan. 1994.

[6] El-Sheikh, G.A., Guidance: Theory and Systems, MTC, 1994, 2004, 2010

[7] El-Sheikh, G.A., Advanced Guidance and Control Systems, MTC, 2010

[8] Harrison, N. J., Electro-Optics Handbook, RCA Corporation, 1974.

[9] Hudson, R. D. , Infrared System Engineering, Wily-Interscience, New York, 1969.

[10]Ljung, L., System Identification: Theory for the User, Prentice-Hall, 1987.

[11]Seyrafi, K. and S. A. Hovanessian, Introduction to Electro-Optical Imaging and Tracking Systems, UK, 1993.

[12] Soderstrom, T. and P. Stoica, System Identification, Prentice Hall, 1989. 